\title{
A scoping review of trials for cell-based therapies in human spinal cord injury
}

\author{
Alice G. Willison $\mathbb{1}^{1} \cdot$ Sam Smith $\mathbb{1}^{2} \cdot$ Benjamin M. Davies ${ }^{3} \cdot$ Mark R. N. Kotter $\mathbb{D}^{3,4} \cdot$ Susan C. Barnett $\mathbb{D}^{5}$
}

Received: 25 August 2019 / Revised: 9 March 2020 / Accepted: 12 March 2020 / Published online: 6 April 2020

(c) The Author(s), under exclusive licence to International Spinal Cord Society 2020

\begin{abstract}
Introduction Spinal cord injury (SCI) is associated with significant and life-long disability. Yet, despite decades of research, no regenerative treatment has reached clinical practice. Cell-based therapies are one possible regenerative strategy beginning to transfer to human trials from a more extensive pre-clinical basis.

Methods We therefore conducted a scoping review to synthesise all cell-based trials in SCI to consider the current state of the field and the cell transplant type or strategy with greatest promise. A search strategy of MEDLINE returned 1513 results. All clinical trials including adult human patients with acute or chronic, compete or incomplete SCI and a recorded ASIA score were sought. Exclusion criteria included non-traumatic SCI, paediatric patients and animal studies. A total of 43 studies, treating 1061 patients, were identified. Most trials evaluated cells from the bone marrow (22 papers, 660 patients) or the olfactory bulb (10 papers, 245 patients).

Results Cell transplantation does appear to be safe, with no serious adverse effects being reported in the short-term. $86 \%$ of trials described efficacy as a primary outcome. However, varying degrees of outcome reporting prevented meta-analysis. No emerging cell type or technique was identified. The majority of trials, 53\%, took place in developing countries, which may suggest more stringent regulatory requirements within Western countries.

Conclusion We believe cell-based transplantation translation remains in its infancy and that, although further robust clinical research is required, it is an important strategy to consider in the treatment of SCI.
\end{abstract}

Supplementary information The online version of this article (https:// doi.org/10.1038/s41393-020-0455-1) contains supplementary material, which is available to authorised users.

Mark R. N. Kotter

mrk25@cam.ac.uk

$\triangle$ Susan C. Barnett

Susan.Barnett@glasgow.ac.uk

1 Northern Foundation School, Newcastle Upon Tyne University Hospitals, Newcastle, UK

2 University of Cambridge School of Clinical Medicine, Cambridge, UK

3 Academic Neurosurgery Unit, Department of Clinical Neurosurgery, University of Cambridge, Cambridge, UK

4 WT MRC Cambridge Stem Cell Institute, Anne McLaren Laboratory, University of Cambridge, Cambridge, UK

5 Institute of Infection, Immunity and Inflammation, College of Medical, Veterinary and Life Sciences, University of Glasgow, Glasgow, UK

\section{Introduction}

Individuals suffering a spinal cord injury (SCI) present an important challenge. Regarding treatment, not only is the biological nature of the condition complex, but also the vulnerability of those affected proposes ethical complexities. Currently, the most efficacious treatment for SCI is early surgical decompression and stabilisation, if necessary, combined with neurorehabilitation to support any spontaneous recovery over time [1]. The limited capacity of the central nervous system (CNS) for renewal and repair has prompted extensive research efforts over the past 20 years, aimed at developing therapies that can improve recovery after SCI [2]. As part of these, stem and progenitor cell-based therapies have come to the forefront of SCI research and have been recognised by the James Lind Alliance Priority Setting Partnership as research priorities (http://www.jla.nihr.ac.uk/). In general, cell transplantation approaches have two aims. Either the transplanted cells participate in repair by integration into the spinal cord and by replacing lost tissue, such as is the 
case of, e.g., neural stem cells/olfactory glia. Alternatively, cells play a transient role as mediators of reparative tissue remodelling [3,4] such as mesenchymal stromal cells (MSCs).

Many cell types have been studied, ranging from embryonic stem cells (ESCs) and neural stem cells (NSCs), derived from embryonic, adult and foetal tissue, to induced pluripotent stem cells (iPSCs) and MSCs, derived from bone-marrow (BM-MSCs), olfactory mucosa (OM-MSCs) and the umbilical-cord (UCD-MSCs) [5-11]. Apart from stem cells, a particular focus has been made on olfactory ensheathing cells (OECs), a glial subtype that has the exclusive ability to support regeneration of olfactory receptor neurons transiting into the CNS from the peripheral nervous system (PNS) [12]. When transplanted into the CNS, OECs can promote the regrowth of axons as well as form myelin sheaths [13]. Within the PNS, myelination is mediated by Schwann cells (SCs). Both OECs and SCs have shown preclinical promise and have been selected for transplantation in human trials [14-16]

However, the nature of human clinical trial data is sparse and limited, and so the current status of cell-based therapy translation remains unclear. Assessing the safety of these therapies is of particular importance as concerns of tumorigenicity have been raised, particularly regarding ECS/iPSC transplant [17]. There is also uncertainty regarding the most efficacious cell type and how these therapies should best be delivered. This scoping review therefore intends to establish the current status of cell-based therapies for SCI by identifying and considering the findings of so far reported human trials.

\section{Methodology}

\section{Protocol and registration}

The overall objectives and methodology of this study were approved by the investigators and the study registered with PROSPERO (ID CRD42017073483).

The objectives were to:

1. Describe the cell types used in human trials;

2. Describe the extraction and delivery methodologies for stem cell transplant;

3. Establish the safety profile for tissue-based therapy and delivery mechanism;

4. Establish methodological factors that enhance efficacy, such as adjuvant therapy or multiple dosing;

5. Demonstrate trends in research themes;

6. If possible, to perform a meta-analysis to consider efficacy of stem cell transplant.

\section{Eligibility criteria}

Inclusion criteria were all trials of tissue-based transplant therapy in human traumatic SCI that used the American Spinal Injury Association (ASIA) Impairment Scale for outcome analysis. The ASIA scale is an objective and well-validated measurement tool, which in the present context provided a criterion for a minimal quality standard. Acute and chronic, complete and incomplete SCI patients were included. Studies unsuitable in the catchment of the initial 1513 results involved animal models, paediatric populations, fewer than 2 patients or non-traumatic SCI and were therefore excluded (see supplementary Appendix 1 for the PRISMA flow diagram).

\section{Information sources, search and study selection}

A search strategy was designed for the MEDLINE database via PubMed (PubMed National Centre for Biotechnology Information, National Library of Medicine, MD USA 20894) (see supplementary Appendix 2 for the search strategy template). Relevant Keywords and MESH terms were initially identified by screening pre-identified review articles [18-20] and developed, in concert with a medical librarian, with reference to the MESH taxonomy and author-selected terms. Search results and the references of included articles were screened by two reviewers (SS and AGW) for relevance.

\section{Data collection and data items}

Data were extracted using a piloted template by two authors independently (SS and AGW), with any discrepancies resolved by mutual discussion and the involvement of a third reviewer (BMD), if required. In order to assess the stage of translation for a therapy or technique, trials were assigned as either Phase 1 or earlier, Phase 2 or Phase 3 using criteria developed by the authors to allow retrospective classification (Fig. 1). Extracted characteristics included: location of trial centre; ethical approval; study characteristic (phase, randomisation, controlled or uncontrolled); primary end point; number of patients; chronicity and location of SCI; patient demographics; presence of ASIA scoring; cell type

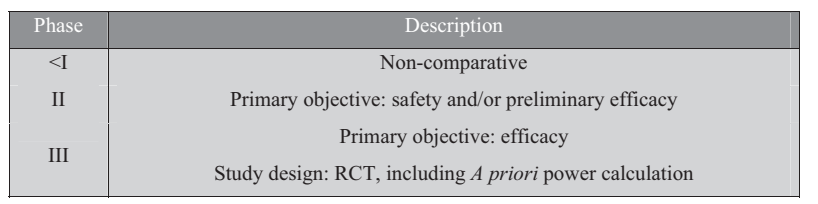

Fig. 1 Criteria for clinical trail phases. Phase I and prior trials are non-comparative. Phase II trials primarily assess safety, with some also establishing preliminary efficacy. Phase III trials establish efficacy and are randomised, controlled trials (RCT) that have an included a priori power calculation. 
Fig. 2 Geographical location of studies. Studies were predominantly from developing countries, with China generating the highest number of publications $(9,21 \%)$, followed by Korea $(5,12 \%)$, Brazil $(3,7 \%)$ and $\operatorname{Iran}(3,7 \%)$.

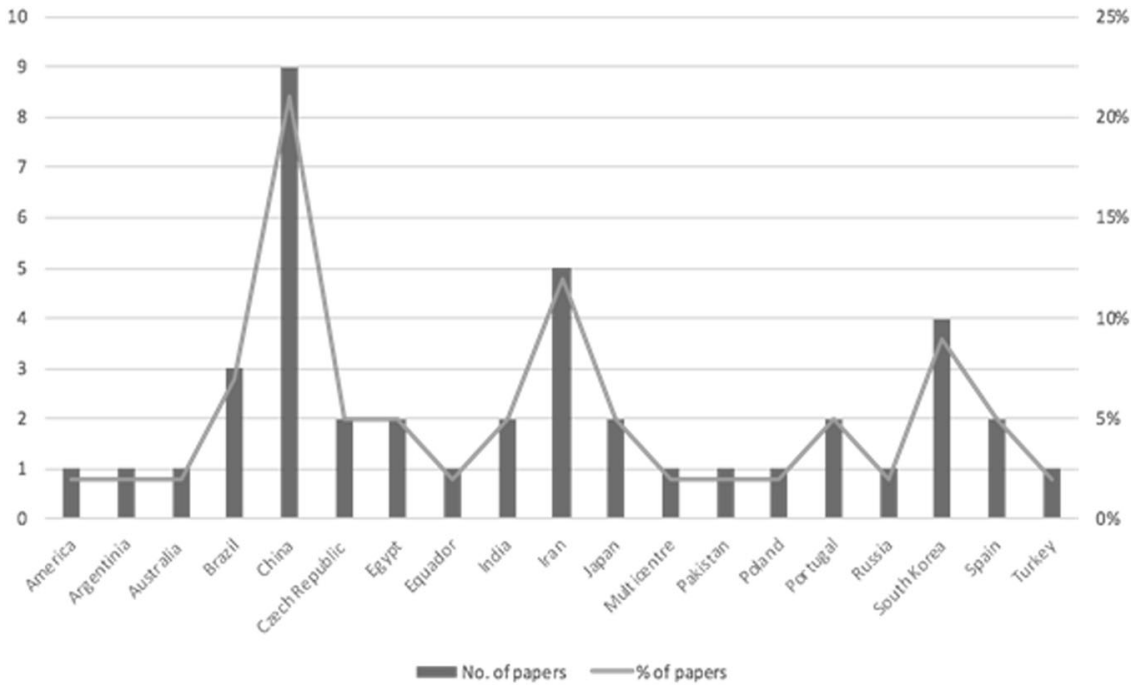

transplanted; extraction and culture (if relevant) methodologies; delivery methodology; presence of neurorehabilitation; use of MRI imaging; follow-up; recovery values in terms of the ASIA score (sensorimotor and functional recovery); serious of life-threatening complications of cell transplant or delivery methodology; relevant comments (identified prognostic indicators). Authors defined patients as acute if the transplant occurred within 6 weeks of injury or chronic if the transplant occurred after 6 weeks.

\section{Synthesis of results}

Data extracted from each study were synthesised and analysed using Microsoft Excel.

\section{Risk of bias assessment}

All included studies underwent risk of bias analysis using the Cochrane Risk of Bias Tool (Cochrane Bias Methods Group, Assessing Risk of Bias in Included Studies, http://methods. cochrane.org/bias/assessing-risk-bias-included-studies): random sequence generation; allocation concealment; blinding of participants and personnel; blinding of outcome assessment; incomplete outcome data; selective reporting; other source of bias. This was also completed by two reviewers independently. Data were compiled using summary statistics.

\section{Results}

\section{Study selection}

The search strategy returned 1513 papers, of which 43 papers were deemed eligible and included for analysis. Together these included data for 1061 patients from 21 countries, involving 12 cell types. Studies were predominantly from developing countries, with China generating the highest number of publications $(9,21 \%)$, followed by Korea $(5,12 \%)$, Brazil $(3,7 \%)$ and Iran $(3,7 \%)$ (Fig. 2).

\section{Study design}

Many studies reported some form of efficacy. However, the overall methodological quality for outcome reporting was low and risk of bias high. Almost $70 \%$ of studies had no comparison arm and $86 \%$ were not randomised. The study design was unspecified in $47 \%$. Additionally, heterogonous study populations, inconsistent outcome assessment and variation in the definition of efficacy made pooled analysis impossible. Only one study was considered a Phase III trial, which was terminated prematurely due to limited efficacy. The majority of trials are Phase I and mostly transplant cells derived from bone marrow. Most cited that ethical approval $(88 \%)$, either from the government $(28 \%)$, hospital $(23 \%)$ or university $(21 \%)$, had been obtained. Despite the scientific methodology being established and, for the most part, unambiguous, the interpretation of patient outcomes was of low methodological quality. The study methodologies have been summarised (see Supplementary Appendix 3 for a detailed account of each article, including the cell type trialled and a summary of the methodology). Therefore, moderate to high risk of bias was prevalent (Fig. 3). Data therefore could not be pooled due to the heterogeneity of reporting, which precluded any meta-analysis.

\section{Populations of spinal cord injury patients involved in trials}

The median age of included patients is 36 years old. Chronic, complete SCI patients alone were trialled in 18 papers $(624$, or $59 \%$ of patients). A mixture of chronic 


\begin{tabular}{|c|c|c|c|c|c|c|c|c|c|c|c|c|c|c|c|c|c|c|c|c|c|c|c|c|c|c|c|c|c|c|c|c|c|c|c|c|c|c|}
\hline Adequate sequence generation & O & $\theta$ & ○ & () & (1) & 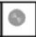 & 0 & 인 & - & () & $\odot$ & () & (6) & 당 & - & () & - & (ن) & (2) & () & - & 0 & 0 & () & (๑) & 0 & O & 0 & (8) & ? & - & - & (•) & $\theta$ & 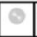 & O & 0 & 0 \\
\hline Allocation concealment & P & (8) & ? & 0 & 0 & $\theta$ & 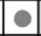 & 인 & 인 & $\theta$ & $\theta$ & ? & $\theta$ & (e) & - & $\theta$ & - & $\theta$ & $\theta$ & () & P & ? & 0 & ๑) & 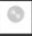 & 0 & 0 & - & $\theta$ & - & O & ○ & $\theta$ & $\theta$ & ( & O & 0 & 0 \\
\hline Blinding & (9) & • & - & ○ & ? & - & - & - & - & (당 & ○ & ○ & P & (6) & - & (e) & O & 앙 & ○ & - & - & - & - & • & $\theta$ & - & O & 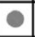 & (e) & - & - & 8 & (8) & - & (8) & O & 0 & O \\
\hline Concurrent therapies similar & - & ? & - & - & (당 & 8 & 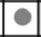 & 앙 & (2) & (9) & ○ & () & O & (2) & 0 & (-) & $\odot$ & - & (2) & - & - & - & (-) & (-) & - & O & (-) & (๑) & (2) & - & • & (•) & (- & (- & (당 & P & (8) & (당 \\
\hline Incomplete outcome data addressed & (†) & (당 & (-) & - & (2) & (2) & 0 & (당 & (2) & (-) & 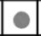 & - & O & $\theta$ & (-) & 0 & - & (e) & $\theta$ & - & $\theta$ & 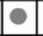 & 0 & - & 인 & - & O & - & $\theta$ & ? & ○ & ○ & (2) & $\theta$ & () & O & 0 & ○ \\
\hline Uniform and explicit outcome definitions & P & - & - & - & ? & (8) & 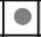 & 항 & - & () & 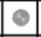 & ○ & () & • & ㄴ) & - & - & - & (2) & - & - & 0 & (2) & - & - & 인 & - & - & (2) & • & - & - & (-) & (-) & (6) & (8) & (2) & (2) \\
\hline Free of selective outcome reporting & P & ? & - & 당 & O & ○ & 0 & . & - & 0 & (6) & - & ○ & $\theta$ & O & 0 & - & • & ○ & 0 & P & - & O & 0 & - & 임 & - & - & 0 & - & - & - & 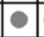 & O & () & P & O & (ా) \\
\hline Free of other bias & P & ? & - & - & (6) & (2) & ○ & . & 0 & (당 & 0 & . & O & ○ & - & 0 & ○ & - & 0 & 0 & - & 0 & - & 0 & - & - & 0 & - & 0 & - & - & - & 0 & O & ○ & P & 0 & e \\
\hline Overall risk of bias & 0 & ? & - & $\theta$ & (당 & (둥 & 0 & $\theta$ & 0 & 앙 & 인 & 0 & O & 0 & 0 & - & - & (•) & 0 & 0 & e & - & 0 & 0 & 인 & - & 0 & 인 & 0 & - & 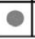 & - & 0 & 0 & 인 & - & 이 & 0 \\
\hline
\end{tabular}

Fig. 3 Risk of bias. Trials were assessed using 9 criteria: adequate sequence generation; allocation concealment; blinding; concurrent therapies similar; incomplete outcome data addressed; uniform and explicit outcome definitions; free of selective outcome reporting; free of other bias; overall risk of bias. Red indicates high risk, amber medium risk and green low risk. Two authors (SS and AW) decided on the risk of bias for each study, based on each criterion.

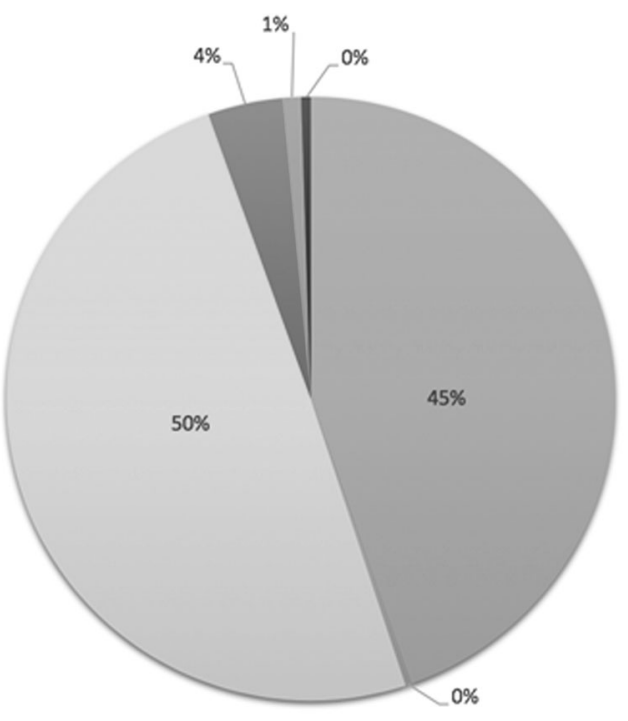

m Cervical $\equiv$ Cervicothoracic $\equiv$ Thoracic $\equiv$ Thoracolumbar $=$ Lumbar $\mathbf{m}$ Conus

Fig. 4 Lesion site. Half of all patients included in the trials suffered a thoracic SCI. The second largest group had cervical injuries. Following this, 4,1 and $0 \%$ of patients had thoracolumbar, lumbar and conus lesions, respectively.

complete and chronic incomplete patients were trialled in 13 papers (250, or $24 \%$ of, patients). A combination of acute complete and chronic complete were the subject of 4 papers (119, or $11 \%$ of, patients). Acute complete patients alone were trialled in 4 papers $(59$, or $6 \%$ of, patients). One paper trialled six patients with an acute incomplete injury and one trialled 10 patients with a chronic incomplete injury. In total, $83 \%$ of patients had a chronic injury. Most injuries were thoracic or cervical (Fig. 4).

\section{Cells trialled in human spinal cord injury}

Nine tissue types were used, most commonly derived from autologous bone marrow (22 papers, 660 patients) and the nasal cavity or olfactory bulb, for autologous or foetal olfactory ensheathing cells (OECs) (10 papers, 245 patients) (Fig. 5, Parts A and B). Umbilical-cord-derived mesenchymal stem cells (UCD-MSCs) were the third most prevalent cell type (3 papers, 40 patients). Most studies transplanted single tissue or cell types, but some used a combination of tissues (4 papers, 27 patients) (Fig. 5, Parts A and B). The following paragraphs will describe, in detail, the methodology for these most frequently trialled cell types.

The bone marrow cell types were further sub-divided into MSCs (12 papers, 231 patients), mononuclear cells (5 papers, 323 patients), bone marrow aspirate ( 2 papers, 51 patients) and cells extracted peripherally from serum postG-CSF treatment (1 paper, 39 patients) (see Supplementary Appendix 3 for a detailed description of methodology). Apart from this latter study, all methodologies began by aspirating bone marrow from the ileum. "Bone marrow aspirate" was taken from the ileum and directly administered to the patient. After marrow aspiration, "mononuclear cells" were separated from blood products by density gradient, often using Ficoll, before being administered. "Stem cells" were derived from the mononuclear cells separated by density gradient, then cultured and characterised, often by cluster of differentiation status, prior to being transplanted. Of note, Oraee-Yazdani et al. [21] administered a combination of "MSCs and Schwann cells" (SCs) in six patients. Oraee-Yazdani et al. gave a combination of "SCs with mononuclear cells" in eight patients. Moviglia et al. [22] combined "mononuclear cells, effector T cells and NSCs" in the "BEN" trial, involving eight patients. In total, 660 patients, $62 \%$ of all patients trialled, were given a bonemarrow-derived cell therapy.

OECs were either foetal ( 3 papers, 17 patients) or autologous (7 papers, 228 patients) (see Supplementary Appendix 3 for a detailed description of methodology). Autologous OECs were either harvested from the nasal mucosa and isolated in culture prior to transplant (1 paper, 3 
A. Breakdown of the Number of Patients Trialed with Each Category of Cell Therapy

\begin{tabular}{|c|c|}
\hline Cell Type & Number of Patients Cell Trailed In \\
\hline Foetal Neurogenic Tissue & 43 \\
\hline Macrophages & 34 \\
\hline Schwann cells (Alone or in Combination) & 25 \\
\hline Olfactory Ensheathing Cells (Isolated or Mucosa) & 245 \\
\hline Umbilical-Cord-Derived Mesenchymal Stem Cells & 40 \\
\hline Bone-Marrow-Derived Cell Therapies & 660 \\
\hline Adipose-Derived Mesenchymal Stem Cells & 14 \\
\hline
\end{tabular}

B. Breakdown of the Number of Articles Trialing Each Cell Therapy

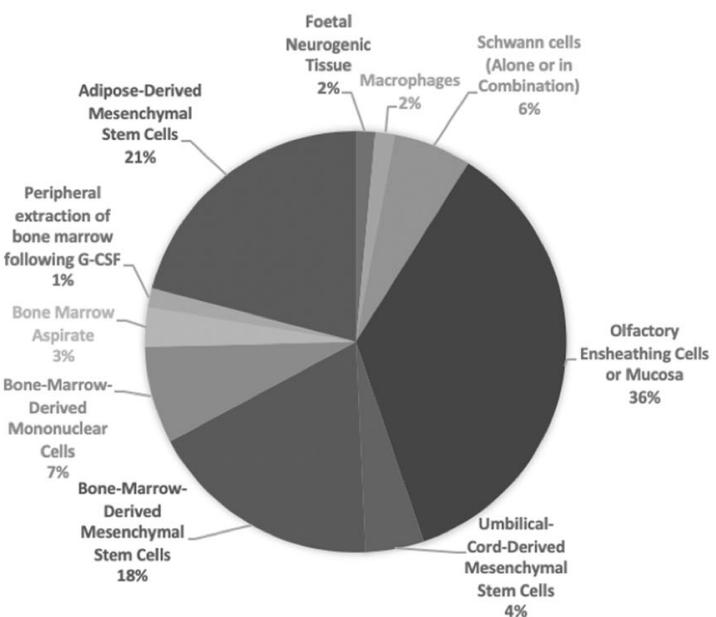

Fig. 5 Cells trialled in human spinal cord injury. Part A describes the number of patients trailled in each category of cell type, with bonemarrow-derived cell therapies including the highest number of patients. Part B illustrates the number of articles researching a given cell therapy. Most articles trailled either bone-marrow-dervied therapies or olfactory tissue.

patients) or transplanted within a graft taken from the nasal mucosa during surgery (4 papers, 38 patients). Foetal OECs were either isolated from the olfactory bulb and cultured prior to transplant (4 papers, 199 patients) or used in combination with foetal Schwann cells (1 paper, 5 patients). In total, OEC transplant, as a monotherapy, was administered to $23 \%$ of all patients.

UCD-MSCs were harvested from the umbilical cord of healthy, term neonates. SCs were taken from the sural nerve, minced and cultured. SCs were more often used as a combinatorial therapy but were once transplanted as a monotherapy (1 study, 6 patients). Macrophages, harvested from a peripheral blood sample and a forearm skin graft, were a further cell type transplanted ( 2 papers, 34 patients). The other cell types were described in single papers. Hur et al. [23] transplanted autologous adipose-derived mesenchymal stem cells, isolated and cultured from autologous lipoaspirate, into 14 patients. A trial by Seledtsova et al. involved 43 patients receiving neurogenic tissue, which was extracted from the brain (foetal nervous tissue) and liver (haematopoietic tissue) of foetuses [24].

\section{Cell delivery methodology and adjuvant therapies}

In general, cells were either administered by lumbar puncture (14 papers, 511 patients), open surgery (22 papers, 557 patients), arterial infusion and/or venous infusion (3 papers, 67 patients) or injection under the guidance of computer tomography (CT) (1 paper, 11 patients) (Fig. 6). In all, 5 different open surgery strategies were identified and 3 different peripheral infusion strategies. Two papers directly compared delivery methods. Of the lumbar puncture group patients, patients were transplanted BM-MNs (4 papers, 315 patients), BM-MSCs (5 papers, 122 patients), UCD-MSCs (1 paper, 22 patients), AD-MSCs (1 paper, 14 patients) or a combination of OECs and BM-MSCs (1 paper, 6 patients). Kishk et al. [25] from the BM-MN group gave an injection of cells once a month for 6 months. Lui et al. [26] gave UCD-MSCs in combination with $5 \mathrm{mg}$ of dexamethasone once a week for 4 weeks [26].

The open surgery group is sub-divided into five groups (OS1-5). OS1 were given open surgery and an injection of cells into the lesion site, proximal cord and distal cord (14 papers, 349 patients). Of OS1, OECs were transplanted into $53 \%$, BM-BMSc into $12 \%$, BM-MNs into $10 \%$, MPGs into $9 \%$, NSCs into $5 \%$, SCs into $2 \%$ and a combination of OECs and SCs into $1 \%$. Post-operatively, one paper transplanting BM-MNs (37 patients) describes five cycles of granulocyte-macrophage-colony stimulating factor (GMCSF) being injected subcutaneously at dose of $250 \mathrm{~g} / \mathrm{m} 2$ of body surface area daily for first 5 days then monthly over 5 months. One paper transplanting NSCs, administered IV cyclosporine at a dose of $3 \mathrm{mg} / \mathrm{kg}$ for 3 days pre-operatively and 4 days post-operatively. Cyclosporine was given orally for 9 weeks afterwards, with the dose being reduced over time. OS2 had a nasal mucosal graft harvested, diced and transplanted into the cyst cavity in one single procedure (4 papers, 38 patients). OS3 included patients given an injection of cells into the lesion proper and the surrounding subarachnoid space (2 papers, 35 patients). One trial gave granulocyte-colony stimulating factor (G-CSF) for 5 days prior to bone marrow aspiration of bone marrow (19 patients). Of this group, 19 were given BM-MNs and 16 BM-MSCs. OS4 were given an additional injection of BMMSCs on the day of surgery and at weeks 4 and 8 (1 paper, 10 patients). The final group, OS5, were treated depending on the presence or absence of a cyst (1 paper, 43 patients). In the presence of a cyst, this was drained and filled with foetal neurogenic tissue (FNT) and a lumbar puncture of cell transplant followed. In the absence of a cyst, cells were transplanted by lumbar puncture alone. 


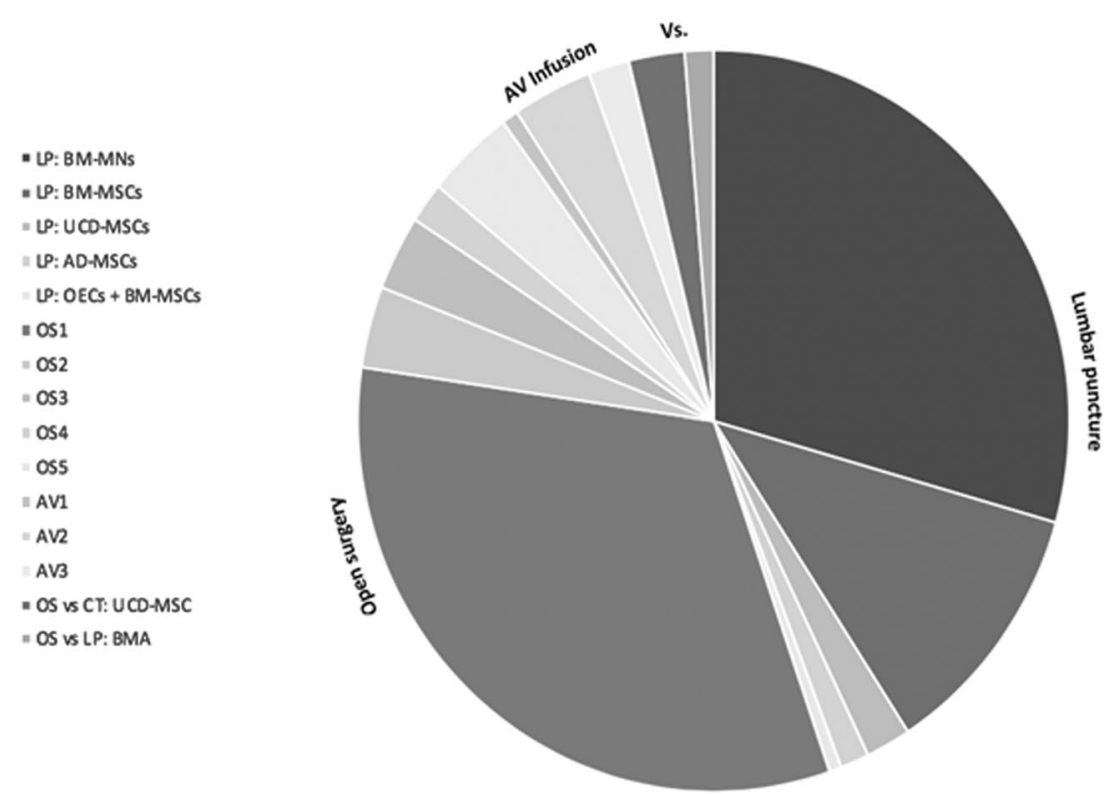

Fig. 6 Distribution of techniques. Five cells types were administered by lumbar puncture (LP): bone-marrow-derived mononuclear cells (BM-MNs) (315 patients, 29\%); bone-marrow-derived mesenchymal stem cells (BM-MSCs) (122 patients, 11\%); umbilical-cord-derived mesenchymal stem cells (UCD-MSCs) (22 patients, 2\%), adiposederived mesenchymal stem cells (AD-MSCs) (14 patients, 1\%); and a mixture of olfactory ensheathing cells and bone-marrow-derived mononuclear cells (OECs + BM-MSCs) (6 patients, 1\%). Open surgery was divided into five groups. OS1 were given open surgery and an injection of cells into the lesion site, proximal cord and distal cord (349 patients, 33\%). OS2 had a nasal mucosal graft harvested, diced

The final three papers gave arterial infusion (IA) and/or venous infusion (IV) (AV1-3). In AV1, which is the BEN trial, patients received IA BM-MNs followed by, 18 days later, IV spinal cord specific ETCs and IA NSCs (1 paper, 8 patients). AV2 gave G-CSF and extracted the mobilised cells in a peripheral blood sample, to be injected into the spinal artery at the level of injury (1 paper, 39 patients). Finally, AV3 divided the patients into two groups. One group received IV BM-MNs and one IA BM-MNs into a spinal artery at the level of the injury (1 paper, 20 patients). One paper transplanted UCD-MSCs under CT-guidance into 11 patients. A second paper compared the transplant of UCD-MSCs by CT-guidance to open surgery in 18 patients, with half assigned to each delivery method. The transplant of BMA by either lumbar puncture or open surgery was also compared by one study.

Towards the two studies that compared delivery methods, the first transplanted UCD-MSCs and included a CTguided delivery arm. Specifically, Dai et al. [27] selected 27 patients with chronic complete SCI to be randomised into two treatment groups (A and B) and a control group (C). Group A underwent open surgery and group B CTguided transplant. Six months after surgery, group A showed an improvement in ASIA score for pain sensation and transplanted into the cyst cavity in one single procedure (38 patients, 4\%). OS3 included patients given an injection of cells into the lesion proper and the surrounding subarachnoid space (35 patients, $3 \%)$. OS4 were given an additional injection of BM-MSCs on the day of surgery and at weeks 4 and 8 (19 patients, 2\%). OS5, were treated depending on the presence or absence of a cyst (43 patients, $4 \%$ ). Two studies compared delivery methods. The first transplanted UCD-MSCs and included a CT-guided delivery arm (27 patients, 3\%). The second transplanted autologous BMA by open surgery or lumbar puncture (14 patients, $1 \%$ ).

$(p=0.006)$, light touch $(p=0.008)$ and ASIA total score $(p=0.009)$. Group B demonstrated the most improvement in ASIA scoring for motor (0.008), pain (0.002) and light touch $(0.004)$, as well as ASIA total score $(0.002)$. No significant differences were seen in group $\mathrm{C}$. The second comparison trial by Chhabra et al. [28] transplanted autologous BMA by open surgery or lumbar puncture into 14 patients with acute SCI. No significant difference in ASIA score improvement was demonstrated at 6 or 12 months between groups.

\section{Multiple dosing regimens}

In all, 6 papers described multiple dosing regimens. Liu et al. [26] administered UCD-MSCs via lumbar puncture at a dose of $1 \times 10^{6}$ cells per $\mathrm{kg}$ with $5 \mathrm{mg}$ of dexamethasone once a week for 4 weeks. BM-MSCs were given by El-khier et al. [29] by lumbar puncture once a month until a cumulative dose of $2 \times 10^{6}$ cells $/ \mathrm{kg}$ was reached, with a median of four injections and a range of 1-8. Kishk et al. [25] transplanted $5 \times 10^{6}$ to $10 \times 10^{6}$ BM-MSCs by lumbar puncture every month for 6 months, with one patient developing encephalomyelitis. BM-MSCs were transplanted by Satti et al. [30] via lumbar puncture at a dose of 
Improved perianal sensation

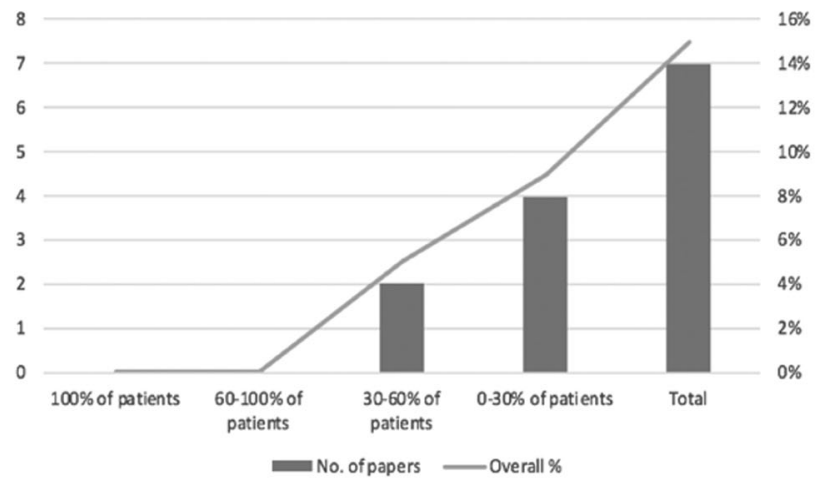

Functional improvement of erection status (\% of males in study)

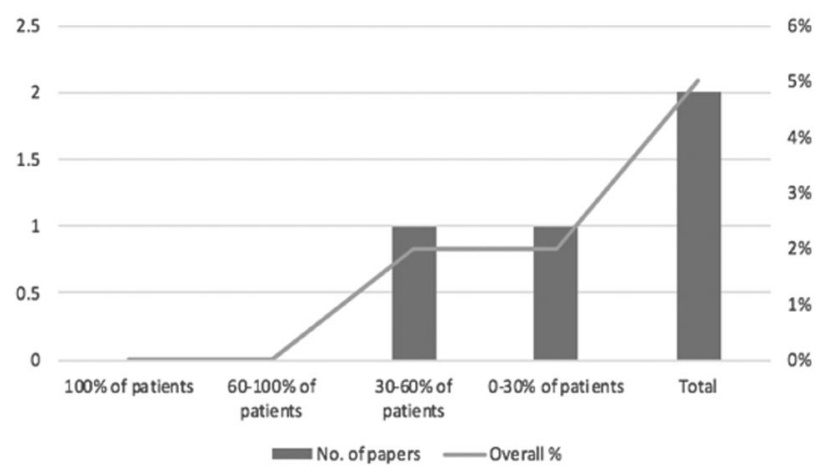

Fig. 7 Reported outcomes. Results are separated into papers that describe $100 \%$ of patients recovering function, then $60-100 \%$ of patients, then $30-60 \%$ of patients, then $0-30 \%$ of patients. In addition, the total number of patients demonstrating improvement is also recorded. Mostly, $0-30 \%$ of patients were reported to recover sensory, motor or sensory and motor function. The graphs show improvements

$1 \times 2 \times 10^{6}$ cells $2-3$ times a day on days 1,48 and 96 . In the Seledtsova et al. [24] paper trialling FNT, two doses were given to patients with a cystic lesion as the cyst was first filled with cell transplant, then cells were again transplanted by lumbar puncture. In all, $8 \times 10^{6} \mathrm{BM}-\mathrm{MSCs}$ were injected by open surgery in the Park et al. [31] trial, followed by $4 \times 10^{7}$ cells injected into the intradural space during this procedure. At 4 and 8 weeks, a further $5 \times 10^{7}$ cells were injected by lumbar puncture. Vaquero et al. [32] gave BM-MSCs by subarachnoid lumbar puncture at a dose of $3 \times 10^{7}$ cells at day 1 , then at 4,7 and 10 months. Finally, Hur et al. administered $9 \times 10^{7}$ AD-MSCs on day 1 , at 1 and 2 months by lumbar puncture [23].

\section{Safety profile of transplant delivery}

Only Kishk et al. [25] reported a serious adverse event in one patient. This trial had a multiple dosing regimen of BMMNs once a month for 6 months. A 27-year-old female, with a history of post-infectious myelitis, developed acute disseminated encephalomyelitis $6 \mathrm{~h}$ after the third cell injection by lumbar puncture.
Improved bladder sensation and function

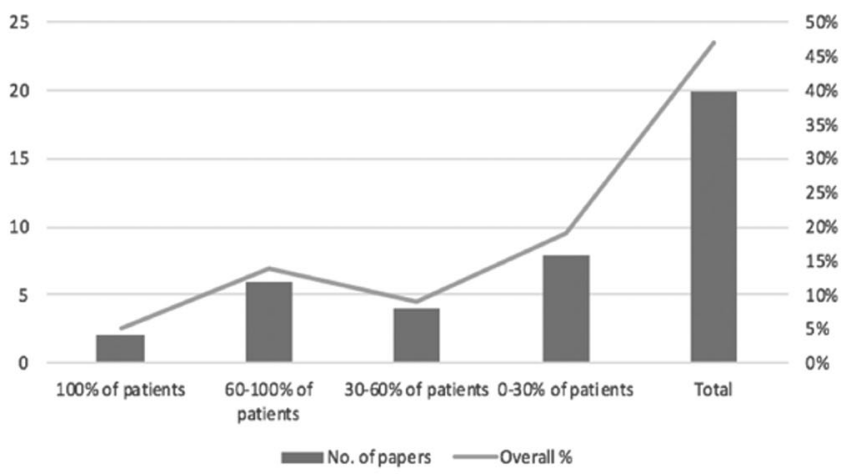

Improved bowel control

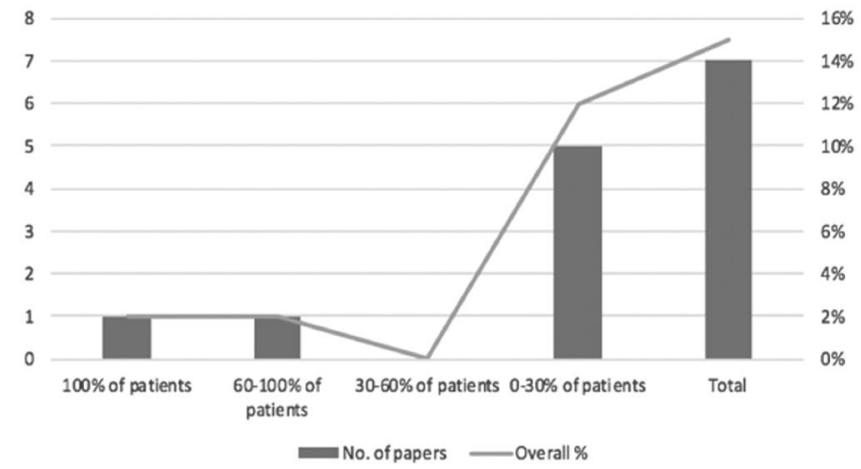

in perianal sensation, bladder sensation and function, erection status in males, and improvement in bowel control. Again, these data are separated into the percentage of patients described to have an improvement in the given function, and do not reflect an amount of recovery, nor pre-defined change in ASIA score.

\section{Safety profile of transplant technique}

No serious complications were reported for delivery by open surgery, lumbar puncture, arterial infusion or venous infusion. Multiple dosing regimens demonstrated no increased risk of procedural complications. Similarly, adjuvant therapies did not appear to negatively impact on the rate of complications.

\section{Outcome reporting}

Due to the heterogeneity in outcome reporting across trials, it is challenging to comment on improvement in sensorimotor function. Close to $80 \%$ of studies commented on sensory function and just over $70 \%$ on motor function in patients. Sensory recovery was most often reported to be observed in $30-60 \%$ of patients and motor recovery in $0-30 \%$ of patients. The majority of papers reported that few patients demonstrated improvement in both modalities. Bladder control and function was an outcome measure in $40 \%$ of trials. Only $14 \%$ of studies commented on perianal sensation and improvement bowel control. In all, 5\% 


\begin{tabular}{|c|c|c|c|c|c|c|c|c|c|c|c|c|c|c|c|c|c|c|c|c|c|c|c|c|c|c|c|c|}
\hline \multirow[t]{2}{*}{ Study } & \multirow[t]{2}{*}{$\mathbf{N}$} & \multirow[t]{2}{*}{$\begin{array}{c}\text { Primar } \\
\text { y } \\
\text { Out. }\end{array}$} & \multirow[t]{2}{*}{ Design } & \multicolumn{5}{|c|}{ Injury Level (\%) } & \multicolumn{4}{|c|}{ Injury Type (\%) } & \multicolumn{10}{|c|}{ Cell Type } & \multicolumn{6}{|c|}{ Out. (\%) } \\
\hline & & & & Ce. & $\begin{array}{l}\text { Ce. } \\
\text { Th. }\end{array}$ & Th. & $\mathbf{L}$ & Cn & $\mathrm{AC}$ & AI & CC & $\begin{array}{l}\text { C } \\
\text { I }\end{array}$ & $\begin{array}{c}\text { OE } \\
\mathrm{C}\end{array}$ & $\begin{array}{l}\text { OE } \\
\text { C+ } \\
\text { SC }\end{array}$ & $\begin{array}{l}\text { BMD } \\
\text {-MSC }\end{array}$ & $\begin{array}{c}\text { BM } \\
\text { A }\end{array}$ & $\begin{array}{c}\text { UCD } \\
\text { MSC }\end{array}$ & $\begin{array}{c}\text { AD- } \\
\text { MSC } \\
\mathbf{S}\end{array}$ & $\underset{G}{M P}$ & $\begin{array}{l}\text { BM- } \\
\text { MNs }\end{array}$ & $\begin{array}{l}\text { Ns } \\
\text { C }\end{array}$ & $\begin{array}{l}\mathrm{s} \\
\mathrm{c}\end{array}$ & $\mathrm{s}$ & м & $\begin{array}{l}\mathbf{S}+ \\
\mathbf{M}\end{array}$ & в & P & $\underset{E}{A /}$ \\
\hline Chen et al & 5 & Safety & RCT & 100 & & & & & & & 100 & & & $\sqrt{ }$ & & & & & & & & & 40 & 100 & 40 & N/A & N/A & \\
\hline Cheng et al & 11 & Safety & RCT & & & & & & & & 100 & & & & & & $\sqrt{ }$ & & & & & & N/A & 100 & N/A & 100 & N/A & \\
\hline Dai et al & 20 & Safety & RCT & 100 & & & & & & & 100 & & & & $\sqrt{ }$ & & & & & & & & 100 & 40 & 40 & 100 & N/A & \\
\hline Wang et al & 8 & Safety & RCT & & & 100 & & & & & 100 & & $\sqrt{ }$ & & & & & & & & & & 25 & 25 & N/A & 25 & 25 & \\
\hline $\begin{array}{c}\text { Elkhier et } \\
\text { al }\end{array}$ & 50 & Safety & RCT & 20 & & 80 & & & & & 30 & 70 & & & $\sqrt{ }$ & & & & & & & & 46 & 52 & 46 & N/A & N/A & \\
\hline $\begin{array}{c}\text { Chhabra et } \\
\text { al }\end{array}$ & 14 & Safety & RCT & & & 100 & & & 100 & & & & & & & $\sqrt{ }$ & & & & & & & & & & & & \\
\hline $\begin{array}{c}\text { Lammertse } \\
\text { et al }\end{array}$ & 26 & Safety & RCT & 45 & & 55 & & & 100 & & & & & & & & & & $\sqrt{ }$ & & & & 19 & & & 26 & 34 & \\
\hline Kishk et al & 43 & Safety & NRCT & $14 \mid$ & & 86 & & & 28 & & 72 & & & & $\sqrt{ }$ & & & & & & & & & 41 & & & & 2 \\
\hline $\begin{array}{c}\text { Tabakow et } \\
\text { al }\end{array}$ & 3 & Safety & NRCT & & 100 & & & & 100 & & & & $\sqrt{ }$ & & & & & & & & & & 100 & 100 & 100 & 66 & N/A & \\
\hline Shin et al & 19 & Safety & NRCT & & & & & & 89 & & 11 & & & & & & & & & & $\sqrt{ }$ & & 35 & 59 & 21 & N/A & N/A & \\
\hline Yoon et al & 37 & Safety & NRCT & & 38 & & & 68 & 32 & & & & & & & & & & & $\sqrt{ }$ & & & 19 & 19 & 19 & N/A & N/A & \\
\hline $\begin{array}{c}\text { Anderson et } \\
\text { al }\end{array}$ & 6 & Safety & NRCT & & & 100 & & & & 100 & & & & & & & & & & & & $\sqrt{ }$ & 83 & & & & & \\
\hline Hur et al & 14 & Safety & NRCT & $43 \mid$ & 7 & 43 & 7 & & & & 85 & 15 & & & & & & $\sqrt{ }$ & & & & & 71 & & & & & \\
\hline
\end{tabular}

Fig. 8 Results of cell transplantation. Comparative studies were selected for outcome analysis. The outcomes in this table are those that were reported by the authors. " $N$ " signifies the number of patients. The primary outcome and design are further study characteristics given. Injury level was either cervical (Ce.), cervicothoracic (Ce. Th.), thoracic (Th.), lumbar (L.), or conus (Cn.). Injury type included acute complete (AC), acute incomplete (AI), chronic complete (CC), and chronic incomplete (CI). Cell types were olfactory ensheathing cells (OECs), olfactory ensheathing cells and Schwann cells (OECs + SCs), bone-marrow-derived mononuclear cells (BM-MNs); bone-marrowderived mesenchymal stem cells (BM-MSCs); umbilical-cord-derived mesenchymal stem cells (UCD-MSCs), adipose-derived mesenchymal stem cells (AD-MSCs), bone marrow aspirate (BMA), macrophages (MPG), neural stem cells (NSCs), and Schwann cells (SCs). Outcomes were recovery of sensation $(\mathrm{S})$, motor function $(\mathrm{M})$, both $\mathrm{S}$ and $\mathrm{M}$, bladder control (B), perianal sensation $(\mathrm{P})$. Few adverse effects $(\mathrm{A} / \mathrm{E})$ of cell transplant were reported. commented on improvement of erection status (Fig. 7). The 13 studies that included control groups and therefore more reliably reported outcomes are summarised in Fig. 8.

\section{Discussion}

\section{Summary of findings}

Cells derived from bone marrow and the olfactory systems were the most popular types used for transplantation-based therapies. Across studies, lumbar puncture was the principle methodology used, followed by open surgery. Adjuvant therapies included dexamethasone, cyclosporine, GM-CSF and G-CSF. Multiple dosing regimens were included by 6 studies. [23, 25, 26, 30, 32, 33]. Comparative studies were performed by Dai et al. [27] and Chhabra et al. [28]. Towards the former, enhanced recovery was observed with the delivery of UCD-MSCs by CT-guided transplant compared to open surgery. Chhabra et al. found no significant difference between lumbar puncture and open surgery for the transplant of BMA. There were no reported serious or life-threatening side effects that resulted from stem cell therapy or delivery methodologies. No single cell type was found to be preferentially researched over time compared to the other cell types (Fig. 9). It was noted that the majority of studies came from developing countries. Finally, whilst many human clinical trials in SCI report promising data for the efficacy of stem cell transplant, the risk of bias is high and study subject number low.

Consequently, the role for stem cell transplant in treatment of SCI remains unclear and the field remains in a formative stage. Beyond overall efficacy, the studies to date show a number of clear knowledge gaps which will need to be overcome, in order to progress stem cell therapies:

1. Which cell type should be transplanted?

2. When should cells be delivered?

3. How should cells be delivered and how often?

4. Are adjuvant therapies required?

5. What are the criteria for determining efficacy?

6. Is cell transplant safe in the long-term?

Each of these points will now be discussed in turn. 


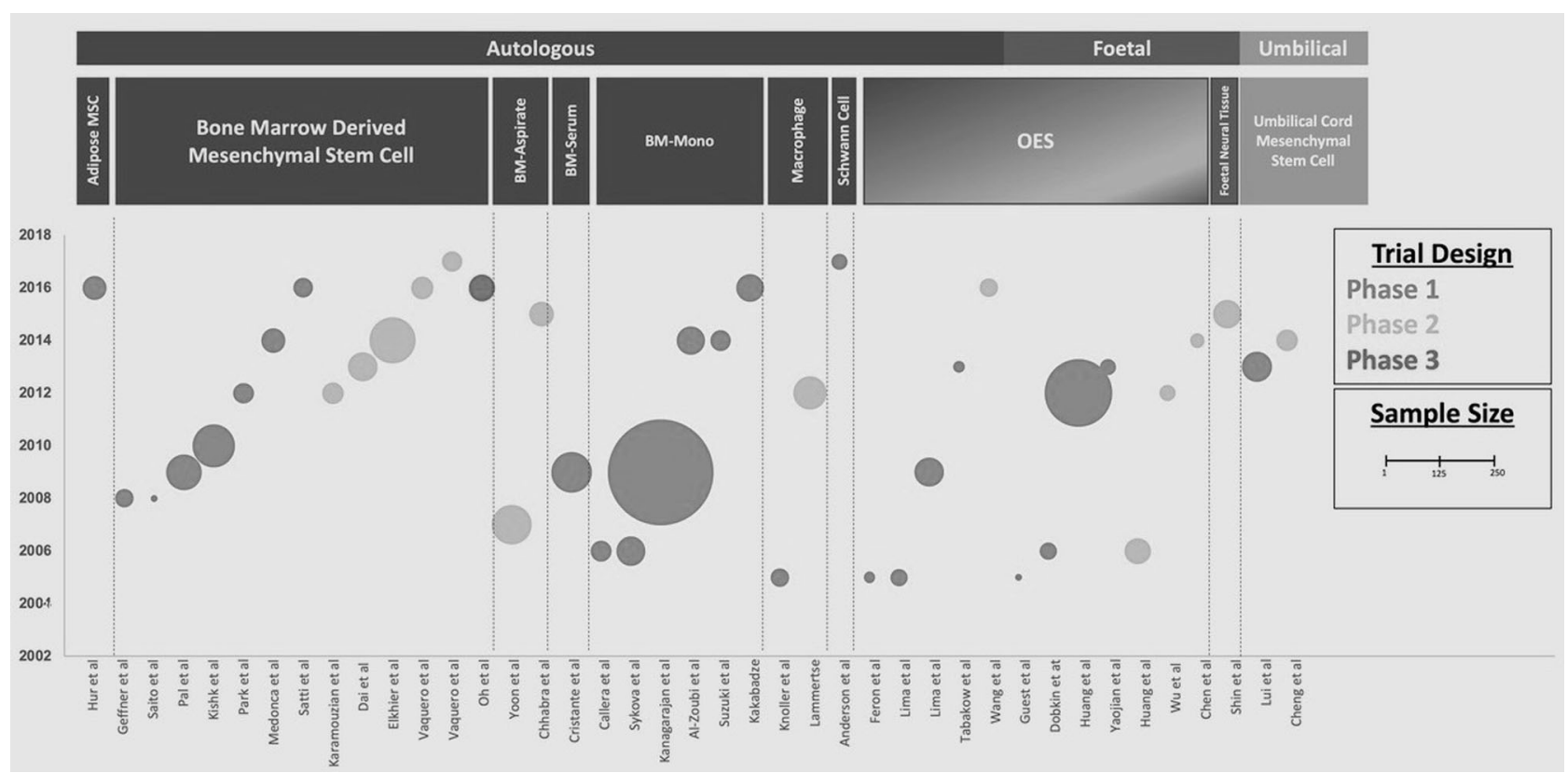

Fig. 9 Trends in research themes. Each bubble represents the sample size, ranging from 1 to 267 . The colour of the bubble is related to the phase of clinical trial, with phase 1 being greed, 2 amber and 3 red. Only one phase 3 clinical trial was identified. The vertical dotted line categorises the cell type, which are categorised into autologous, foetal

\section{Which cell type should be transplanted?}

It is challenging to conclude if any cell type demonstrates the greatest overall efficacy. BMD-MSCs were the most popular cell type. This may be due to ease of extraction compared to cell types that are derived from the olfactory bulb, umbilical cord or foetal tissue. Of the therapies derived from bone-marrow, mononuclear cells are a promising candidate for transplant. Bone marrow aspirate contains tissue fragments, venous blood and various cell types, including mesenchymal stem cells and mononuclear cells [17]. To isolate mononuclear cells, the aspirate is separated by a density gradient [18]. The studies identified by this review often achieved this using Ficoll-Paque ${ }^{\mathrm{TM}}$ products manufactured by GE Healthcare [19]. To further isolate MSCs, cells are cultured and those that adhere are BM-MSCs. For confirmation that the desired cell type is present, cells are characterised by fluorescence-activated cell sorting (FACS) analysis. Therefore, the use of mononuclear cells, which are easier to administer in clinical trials as in vitro expansion is not required, would be practical as a clinical therapy. This would need to be balanced against efficacy. It should be noted that MSCs have been identified from the human biopsies of olfactory mucosa $[4,7,34]$. However, these have not reached clinical trials. With the promise of olfactory ensheathing cells as a candidate, this tissue may provide other more useful cell candidates. or umbilical. Taking any time point on the $y$-axis into consideration, there is no point were one cell type emerges above the rest. This signifies that no one cell type has been increasing in popularity from any one point in time. In other words, there are no trends in research themes.

\section{When should cells be delivered?}

A pertinent question towards cell-transplant-based therapy is whether it would be more efficacious to target acute or chronic SCI. This review has indicated that $83 \%$ of those recruited into clinical trials are chronic SCI patients. When considering efficacy, it may be best that cell transplant-based therapy trial is performed during the initial stabilisation and decompression surgery. An intervention performed before the influx of inflammation and formation of a glial scar may be better placed to succeed [35]. However, patients are extremely vulnerable at this time. Further to this, it is possible that stem cell transplant during this critical phase might impair spontaneous recovery [36]. Chronic injury offers a stable environment in terms of the lesion proper and patient mindset. For preliminary trials, it is understandable that this patient group was the most suitable and was therefore selected. However, moving forward into efficacy trials, a larger cohort of acute or subacute SCI patients would provide valuable outcomes data.

\section{How should cells be delivered and how often?}

Superiority of any one delivery technique is not clear. Across studies, lumbar puncture was the principle methodology used. This is likely to be due to a reduced risk of procedural complications, ease of delivery and cost effectiveness. The rationale for multiple dosing is that a therapeutic level of 
Follow-Up of Patients

60

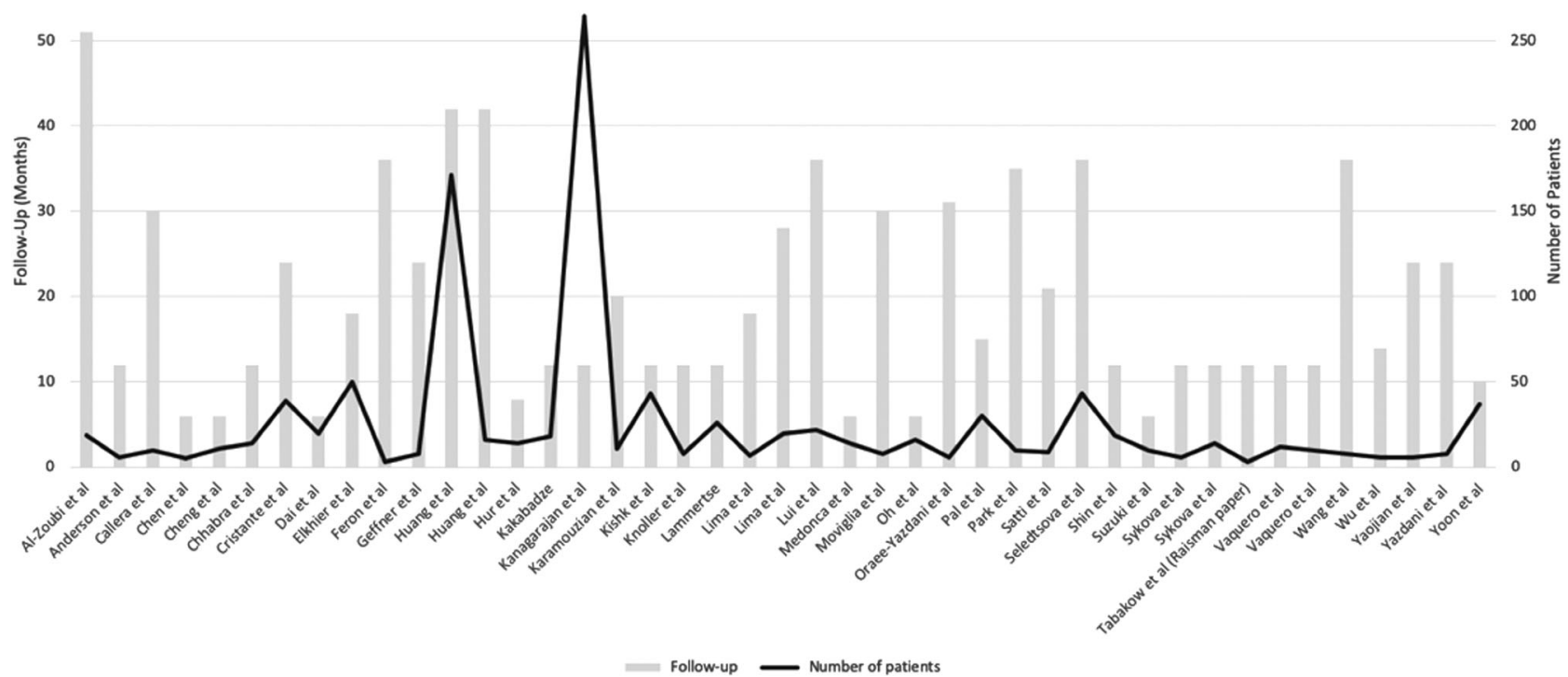

Fig. 10 Follow-up of patients. Follow-up periods are represented by the blue bars. Number of patients is represented by the black line. The follow-up ranged from 6 to 51 months, with an average of 18 months.

transplant tissue is present within or surrounding the lesion for an extended period of time, which may have a positive effect on outcomes. Multiple dosing is inconceivable if numerous open surgeries are required; this strategy is better suited to less invasive techniques. Towards this, injecting cell-based therapies into the venous or arterial circulatory systems may be considered. However, lumbar puncture allows cell-based therapies to be administered more directly and only onto the target site. Considering these factors, lumbar puncture is a promising strategy.

\section{Are adjuvant therapies required?}

With increased understanding of the molecular landscape during primary and secondary phases of spinal cord injury, potential adjuvant treatments that intervene with signalling cascades have been proposed. However, the timing and benefit of these therapies remains controversial. Five clinical trials included adjuvants, which were dexamethasone, cyclosporine, GM-CSF and G-CSF. Lui et al. [26] gave dexamethasone to prevent aseptic chemical meningitis when transplanting UCD-MSCs. Cheng et al. [37] also transplanted UCD-MSCs, but without adjuvants, and reported no incidence of this complication in the 11 patients trialled. To induce immune suppression when transplanting NSCs derived from foetal tissue, Shin et al. [38] gave cyclosporine. Interestingly, five other clinical trials successfully transplanted tissue without immune suppression [24, 39-42]. G-CSF and GM-CSF similarly mobilise haematopoietic stem cells from bone marrow, suppress glial scar formation, induce neurotrophic factors and demonstrate some improvement of functional recovery in animal models [43-45]. There is suggestion in the literature that G-CSF and GM-CSF may be substituted [46]. In two studies, GCSF was given 5 days prior to aspiration of BM-MNs [47] and BMA [48]. Yoon et al. [33] injected GM-CSF after surgery to enhance the efficacy of BM-MN transplant.

\section{What are the criteria for determining efficacy?}

As mentioned, it should be required that clinical trials in $\mathrm{SCI}$ adhere to guidelines that describe conduct and outcome reporting. In 2006, International Campaign for Cures of spinal cord injury Paralysis (ICCP) Clinical Guidelines Panel provided guidance on appropriate and accurate outcome measures, the intention of which being to ensure that the evaluation of an intervention truly demonstrates its efficacy [49]. The ICCP suggests factors to be considered before reporting efficacy. Among these is that the evolution of primary end point from early to late phases of clinical trial must be reflected in the reported outcome. That is, the focus of a Phase 1 trial is safety and that of a Phase 3 is to confirm value in clinical practice. However, many studies were a combination of primary end point reporting from both Phase 1 and 3. Notably, the ICCP state that: Neurological function tests should remain an element of the outcome assessment in Phase 3 trials. In addition, the adoption of a standardised method for reporting outcomes is 
mentioned. Suggested assessment methods for efficacy are the ASIA scale, for physical improvement in impulse transmission within the spinal cord, and the Functional Independence Measure (FIM) or Spinal Cord Dependence Measure (SCIM), to describe any functional changes relevant to the subject's activities of daily living. Further to this, the panel suggest assessment of the subject's societal and cultural perception of him- or herself by a quality of life (QoL) survey.

\section{Is cell transplant safe in the long-term?}

The safety profile of stem cells and their administration was consistently promising. Only one adverse event, encephalomyelitis, was reported by Kishk et al. [25], in the context of previous post-infectious myelitis. However, with followup periods mostly less than 18 months, the long-term safety is yet to be established. Follow-up ranged from 6 to 51 months (Fig. 10). It is noted that an intramedullary spinal cord mass was identified 8 years after Lima et al. [50] trialled olfactory mucosa autograft transplant [51, 52].

\section{Developing countries}

Cell-based transplant therapies, in the short-term, appear to be safe, but their efficacy remains unclear. Research is being led by developing countries, which may signify discrepancies in regulatory approval. The Declaration of Helsinki is accepted as an international standard of human research ethics, promoting informed consent and exercising caution around patient vulnerability. Indeed, SCI is one area of research with particularly vulnerable patients, as the therapies available are limited and the consequences immense. The vast majority (91\%) of clinical trials identified by this scoping review did meet acceptable research standards and had applied for local ethical approval, from governmental or university-led regulatory bodies. However, there remains incongruity in the number of studies from China, Korea and Iran compared to developed countries. It is predicted that with increasing involvement in medical research, the discrepancy observed in principles grounded by virtue ethics will reduce as international regulation becomes increasingly important. Further to this, embryonic stem cell research is not approved in the UK and so clinical trials involving foetal tissue are restricted to a small number of countries, such as China, where it is possible to harvest foetal tissue.

\section{Conclusions and future directions}

This scoping review reports the predominant tissue-based transplant therapies used in clinical trials for the treatment of
SCI. Importantly, cell transplant in SCI appears safe and methodologically feasible. The nature of injury affecting study subjects is mostly chronic complete and therefore unlikely to benefit from therapeutic intervention. Many cell types have been trialled, but with few adjuvant treatments, despite many targeted molecular therapies described in the literature. It would be of interest if later trials included a larger proportion of acute incomplete SCI and included an adjuvant therapy comparison arm. A search of Clinicaltrials. gov demonstrated that few studies included acute SCI as the primary patient demographic and that MSCs remain the most popular cell type to be transplanted in SCI. Interestingly, despite one third of recent clinical trials being completed, the data are mostly unpublished. This may reflect the complexity and uncertainty regarding outcome reporting in SCI. Cell transplant methodologies were similar to those already identified, with no emerging themes. One trial in progress is using the novel NeuroRegen Scaffold. This current review of stem cell therapy in SCI suggests a great need for transparent, ethical and high-level evidence. Of note, a review published since writing this article also discusses criteria for obtaining successful cell transplantation [53]. This scoping review also demonstrates that the risk of bias acts to confound the promising results reported by many trials. Understandably, it is morally challenging to randomise desperate patients and allow control groups to undergo open spinal surgery with no potential therapeutic benefit. When this is considered, it may be that some degree of bias is acceptable. However, this reinforces the need for consistent outcome reporting and the adoption of a standardised method to do so.

Acknowledgements We thank BMA librarian Helen Elwell for her help in identifying relevant articles.

Funding Research in MK laboratory is supported by a core support grant from the Wellcome Trust and MRC to the Wellcome TrustMedical Research Council Cambridge Stem Cell Institute.

Author contributions AGW was responsible for designing the review protocol, writing the protocol and report, conducting the search, screening potentially eligible studies, extracting and analysing data, interpreting results, updating reference lists and creating: Figs. 2-8, 10; Appendices 1, 2 and 3. SS was responsible for reviewing the data extraction and analysis of AGW to ensure correct procedure had been followed. BD was responsible for desigining the review protocol and report, creating Figs. 9 and 1, and contributing to revisions of the article. MK was responsible for revisions of the article. SB was responsible for revisions of the article.

\section{Compliance with ethical standards}

Conflict of interest The authors declare that they have no conflict of interest.

Publisher's note Springer Nature remains neutral with regard to jurisdictional claims in published maps and institutional affiliations. 


\section{References}

1. Ahuja CS, Wilson JR, Nori S, Kotter MRN, Druschel C, Curt A, et al. Traumatic spinal cord injury. Nat Rev Dis Prim. 2017;3:17018.

2. Goldman SA. Stem and progenitor cell-based therapy of the central nervous system: hopes, hype, and wishful thinking. Cell Stem Cell. 2016;18:174-88.

3. Laroni A, Kerlero N, Rosbo D, Uccelli A. Mesenchymal stem cells for the treatment of neurological diseases: immunoregulation beyond neuroprotection. Immunol Lett. 2016;168:183-90.

4. Lindsay SL, Barnett SC. Are nestin-positive mesenchymal stromal cells a better source of cells for CNS repair? Neurochem Int. 2017;106:101-7.

5. Bu X-Y, Huang Z-Q, Zhang Y-F. Transplantation of bone marrow derived mesenchymal stem cells for treatment of spinal cord injury. Chin J Clin Rehabil. 2016;10:183-5.

6. Iwai H, Shimada H, Nishimura S, Itakura Y, Kobayashi G, Hori $\mathrm{K}$, et al. Allogeneic neural stem/progenitor cells derived from embryonic stem cells promote functional recovery after transplantation into injured spinal cord of nonhuman primates. Stem Cells Transl Med. 2015;4:708-19.

7. Lindsay SL, Johnstone SA, Mountford JC, Sheikh S, Allan DB, Clark, et al. Human mesenchymal stem cells isolated from olfactory biopsies but not bone enhance CNS myelination in vitro. Glia. 2013;61:368-82.

8. Manley NC, Priest CA, Denham J, Wirth ED, Lebkowski JS. Human embryonic stem cell-derived oligodendrocyte progenitor cells: Preclinical efficacy and safety in cervical spinal cord injury. Stem Cells Transl Med. 1999;6:1917-29.

9. Mcdonald JW, Liu XZ, Qu Y, Liu S, Mickey SK, Turetsky D, et al. Transplanted embryonic stem cells survive, differentiate and promote recovery in injured rat spinal cord. Nat Med. 1999;5:1410-2.

10. Wang L, Wang L-Z. Neural stem cells for treating spinal cord injury. J Clin Rehabil Tissue Eng Res. 2008;12:2335-8.

11. Yousefifard M, Nasirinezhad F, Shardi Manaheji H, Janzadeh A, Hosseini M, Keshavarz M. Human bone marrow-derived and umbilical cord-derived mesenchymal stem cells for alleviating neuropathic pain in a spinal cord injury model. Stem Cell Res Ther. 2016;7:36.

12. Graziadei PPC, Monti Graziadei AG. Regeneration in the olfactory system of vertebrates. Am J Otolaryngol Neck Med Surg. 1983;4:228-33.

13. Franklin RJM, Gilson JM, Franceschini IA, Barnett SC. Schwann cell-like myelination following transplantation of an olfactory bulb-ensheathing cell line into areas of demyelination in the adult CNS. Glia. 1996;17:217-24.

14. Chen BK, Madigan NN, Hakim JS, Dadsetan M, Mcmahon S, et al. GDNF Schwann cells in hydrogel scaffolds promote regional axon regeneration, remyelination and functional improvement after spinal cord transection in rats. J Tissue Eng Regen Med. 2018;12:398-407.

15. Iwatsuki K, Yoshimine T, Kishima H, Aoki M, Yoshimura K, Ishihara $\mathrm{M}$, et al. Transplantation of olfactory mucosa following spinal cord injury promotes recovery in rats. Neuroreport. 2018;19:1249-52.

16. Watzlawick R, Rind J, Sena ES, Brommer B, Zhang T, Kopp MA, et al. Olfactory ensheathing cell transplantation in experimental spinal cord injury: Effect size and reporting bias of 62 experimental treatments: a systematic review and meta-analysis. PLoS Biol. 2016;14:1-16.

17. Deng J, Zhang Y, Xie Y, Zhang L, Tang P. Cell transplantation for spinal cord injury: tumorigenicity of induced pluripotent stem cell-derived neural stem/progenitor cells. Stem Cells Int. 2018;2018:5653787.
18. Kabu S, Gao Y, Kwon BK, Labhasetwar V. Drug delivery, cellbased therapies, and tissue engineering approaches for spinal cord injury. J Control Release. 2015;219:141-54.

19. Muheremu A, Peng J, Ao Q. Stem cell based therapies for spinal cord injury. Tissue Cell. 2016;48:328-33.

20. Raspa A, Pugliese R, Maleki M, Gelain F. Recent therapeutic approaches for spinal cord injury. Biotechnol Bioeng. 2016;113:253-9.

21. Oraee-Yazdani S, Hafizi M, Atashi A, Ashrafi F, Seddighi AS, Hashemi SM, et al. Co-transplantation of autologous bone marrow mesenchymal stem cells and Schwann cells through cerebral spinal fluid for the treatment of patients with chronic spinal cord injury: Safety and possible outcome. Spinal Cord. 2016;54:102-9.

22. Moviglia GA, Varela G, Brizuela JA, Moviglia Brandolino MT, Farina P, Etchegaray G, et al. Case report on the clinical results of a combined cellular therapy for chronic spinal cord injured patients. Spinal Cord. 2009;47:499-503.

23. Hur JW, Cho T-H, Park D-H, Lee J-B, Park J-Y, Chung Y-G. Intrathecal transplantation of autologous adipose-derived mesenchymal stem cells for treating spinal cord injury: a human trial. J Spinal Cord Med. 2015;39:655-64.

24. Seledtsova GV, Rabinovich SS, Belogorodtsev SN, Parlyuk OV, Seledtsov VI, Kozlov VA. Delayed results of transplantation of fetal neurogenic tissue in patients with consequences of spinal cord trauma. Bull Exp Biol Med. 2010;149:530-3.

25. Kishk NA, Gabr H, Hamdy S, Afifi L, Abokresha N, Mahmoud H, et al. Case control series of intrathecal autologous bone marrow mesenchymal stem cell therapy for chronic spinal cord injury. Neurorehabil Neural Repair. 2010;24:702-8.

26. Liu J, Han D, Wang Z, Xue M, Zhu L, Yan H, et al. Clinical analysis of the treatment of spinal cord injury with umbilical cord mesenchymal stem cells. Cytotherapy. 2013;15:185-91.

27. Dai G, Liu X, Zhang Z, Wang X, Li M, Cheng H, et al. Comparative analysis of curative effect of CT-guided stem cell transplantation and open surgical transplantation for sequelae of spinal cord injury. J Transl Med. 2013;11:315.

28. Chhabra HS, Sarda K, Arora M, Sharawat R, Singh V, Nanda A, et al. Autologous bone marrow cell transplantation in acute spinal cord injury - an indian pilot study. Spinal Cord. 2016;54:57-64.

29. El-Kheir WA, Gabr H, Awad MR, Ghannam O, Barakat Y, Farghali HAMA, et al. Autologous bone marrow-derived cell therapy combined with physical therapy induces functional improvement in chronic spinal cord injury patients. Cell Transpl. 2014;23:729-45.

30. Satti HS, Waheed A, Ahmed P, Ahmed K, Akram Z, Aziz T, et al. Autologous mesenchymal stromal cell transplantation for spinal cord injury: a Phase I pilot study. Cytotherapy. 2016;18:518-22.

31. Park JH, Kim DY, Sung IY, Choi GH, Jeon MH, Kim KK, et al. Long-term results of spinal cord injury therapy using mesenchymal stem cells derived from bone marrow in humans. Neurosurgery. 2012;70:1238-47.

32. Vaquero J, Zurita M, Rico MA, Bonilla C, Aguayo C, Fernández $\mathrm{C}$, et al. Repeated subarachnoid administrations of autologous mesenchymal stromal cells supported in autologous plasma improve quality of life in patients suffering incomplete spinal cord injury. Cytotherapy. 2017;19:349-59.

33. Yoon SH, Shim YS, Park YH, Chung JK, Nam JH, Kim MO, et al. Complete spinal cord injury treatment using autologous bone marrow cell transplantation and bone marrow stimulation with granulocyte macrophage-colony stimulating factor: phase I/II clinical trial. Stem Cells. 2007;25:2066-73.

34. Delorme B, Nivet E, Gaillard J, Häupl T, Ringe J, Devèze A, et al. The human nose harbors a niche of olfactory ectomesenchymal stem cells displaying neurogenic and osteogenic properties. Stem Cells Dev. 2010;19:853-66. 
35. Cheng I, Park DY, Mayle RE, Githens M, Smith RL, Park HY. Does timing of transplantation of neural stem cells following spinal cord injury affect outcomes in an animal model? J Spine Surg. 2017;3:567-71.

36. Cell CS, Bretzner F, Gilbert F, Baylis F, Brownstone RM. Perspective target populations for first-in-human embryonic stem cell research in spinal cord injury. Cell. 2011;8:468-75.

37. Cheng H, Liu X, Hua R, Dai G, Wang X, et al. Clinical observation of umbilical cord mesenchymal stem cell transplantation in treatment for sequelae of thoracolumbar spinal cord injury. J Transl Med. 2014;12:1-8.

38. Shin JC, Kim KN, Yoo J, Kim I-S, Yun S, Lee H, et al. Clinical trial of human fetal brain-derived neural stem/progenitor cell transplantation in patients with traumatic cervical spinal cord injury. Neural Plast. 2015;2015:1-22.

39. Huang H, Chen L, Wang H, Xi H, Gou C, Zhang J, et al. Safety of fetal olfactory ensheathing cell transplantation in patients with chronic spinal cord injury. A 38-month follow-up with MRI. Zhongguo Xiu Fu Chong Jian Wai Ke Za Zhi. 2006;20:439-43.

40. Huang H, Xi H, Chen L, Zhang F, Liu Y. Long-term outcome of olfactory ensheathing cell therapy for patients with complete chronic spinal cord injury. Cell Transpl. 2005;21:23-31.

41. Rao Y, Zhu W, Guo Y, Jia C, Qi R, Qiao R, et al. Long-term outcome of olfactory ensheathing cell transplantation in six patients with chronic complete spinal cord injury. Cell Transpl. 2013;22:21-25.

42. Wu J, Sun T, Ye C, Yao J, Zhu B, He H. Clinical observation of fetal olfactory ensheathing glia transplantation (OEGT) in patients with complete chronic spinal cord injury. Cell Transpl. 2012;21:33-38.

43. Bouhy D, Malgrange B, Multon S, Poirrier A-LL, Scholtes F, Schoenen J, et al. Delayed GM-CSF treatment stimulates axonal regeneration and functional recovery in paraplegic rats via an increased BDNF expression by endogenous macrophages. FASEB J. 2006;20:1239-41.

44. Chen C-H, Huang S-Y, Chen N-F, Feng C-W, Hung H-C, Sung C$\mathrm{S}$, et al. Intrathecal granulocyte colony-stimulating factor modulate glial cell line-derived neurotrophic factor and vascular endothelial growth factor A expression in glial cells after experimental spinal cord ischemia. Neuroscience. 2013;242:39-52.

45. Lee J-S, Yang C-C, Kuo Y-M, Sze C-I, Hsu J-YC, Huang Y-H, et al. Delayed granulocyte colony-stimulating factor treatment promotes functional recovery in rats with severe contusive spinal cord injury. Spine. 2012;37:10-17.

46. Chung J, Kim MH, Yoon YJ, Kim KH, Park SR, Choi BH. Effects of granulocyte colony-stimulating factor and granulocytemacrophage colony-stimulating factor on glial scar formation after spinal cord injury in rats. J Neurosurg Spine. 2014;21:966-73.

47. Al-Zoubi A, Jafar E, Jamous M, Al-Twal F, Al-Bakheet S, Zalloum $\mathrm{M}$, et al. Transplantation of purified autologous leukapheresis-derived CD34+ and CD133+ stem cells for patients with chronic spinal cord injuries: long-term evaluation of safety and efficacy. Cell Transpl. 2014;23:25-34.

48. Cristante AF, Barros-Filho TEP, Tatsui N, Mendrone A, Caldas JG, Camargo A, et al. Stem cells in the treatment of chronic spinal cord injury: evaluation of somatosensitive evoked potentials in 39 patients. Spinal Cord. 2009;47:733-8.

49. Fawcett JW, Curt A, Steeves JD, Coleman WP, Tuszynski MH, Lammertse D, et al. Guidelines for the conduct of clinical trials for spinal cord injury as developed by the ICCP panel:clinical trial outcome measures. Spinal Cord. 2007;45:190-205.

50. Lima C, Escada P, Pratas-Vital J, Branco C, Arcangeli CA, Lazzeri $\mathrm{G}$, et al. Olfactory mucosal autografts and rehabilitation for chronic traumatic spinal cord injury. Neurorehabil Neural Rep. 2010;24:10-22.

51. Dlouhy BJ, Awe O, Rao RC, Kirby PA, Hitchon PW. Autograftderived spinal cord mass following olfactory mucosal cell transplantation in a spinal cord injury patient. J Neurosurg Spine. 2014;21:618-22.

52. Woodworth CF, Jenkins G, Barron J, Hache N. Intramedullary cervical spinal mass after stem cell transplantation using an olfactory mucosal cell autograft. CMAJ. 2019;191:E761-E764.

53. Zholudeva LV, Lane MA. Choosing the right cell for spinal cord repair. J Neurosci Res. 2019;97:109-11. 